are the reports of the psychiatrists called for the Crown and for the defence. The book is concluded with a summary of the Scott-Henderson enquiry into the death of Mrs. Evans.

A series of appendices give fuller details of material used in the text.

The case, with its sexual background, is remarkable for the number of women murdered in the same house and the repeated use of carbon monoxide as a preliminary to strangling. Although the description of such crimes must of necessity be horrible, the importance of this publication to those engaged in medico-legal work is very great. Dr. Camps's writing is admirable for its conciseness, and his book could well be used as a model for future works.

W.M.D.

\section{STEDMAN'S MEDICAL DICTIONARY}

Edited by Norman BUrke Taylor, V.D., M.D., F.R.S.C., F.R.C.S., F.R.C.P., M.R.C.S. 18 th Edition. Pp. xliv + I $_{56} \mathrm{~J}$, with 500 illustrations and 22 plates, six in colour. London: Baillière, Tindall \& Cox, Ltd. r954. 63s.

Such is the expansion of medical language that new editions of this dictionary have appeared at intervals of four years. The 16 th edition in 1946 still maintained the title of a practical medical dictionary and could then be published at twothirds of the price of the I 8 th edition, which, despite its comprehensive scope, has been produced at a reduction of three shillings when compared with the I 7 th edition. The retention of 'practical' in the title would have proved misleading, since the dictionary is in no sense a work confined to words in general use; there is even a tendency to stray beyond what might strictly be regarded as medicine into matters zoological. The sea-anemone is both described and illustrated, while the sea-urchin must be content with verbal definition only. Proper names abound and anyone baffled by a syndrome or structure labelled with its discoverer's name may expect to find the answer in this dictionary, together with the date and nationality of the individual concerned-a rare asset in a clinical world still addicted. and properly so, to erecting memorials through nomenclature. One name does not appear in the dictionary, but only on its title page; a short account of Stedman or the inclusion of his original preface would enhance the work. The contents have been brought well up to date; for example, the latest antibiotic substances are defined and their chemical formulae given where possible. There is a valuable opening chapter on etymology, while there are useful appendices on symbols, nomenclature, weights, measures and scales; figures for the standard weight according to height and age are included, but without reference to their origin. For English users the American form of spelling is a disadvantage; otherwise there is only one serious criticism. The book is illustrated with over 500 pictures, most of which are superfluous, since the definitions are adequate without them and the majority are sadly lacking in artistry. B.N.B.

\section{STONE IN THE URINARY TRACT}

By H. P. Winsbury-White, M.B., Ch.B., F.R.C.S. 2nd Edition. Pp. ix +342 , with $\mathrm{r} 44$ illustrations. London: Butterworth \& Co., Ltd. 1954. 63 s.

In the second edition of his book, Stone in the Urinary Tract, Mr. Winsbury-White is, for all practical purposes, presenting a new volume, for most of the text has been rewritten.

The value of the book is difficult to assess, for it is too long a work for most candidates for higher examinations to have time to read and yet it does not give the detail of a full reference work. The book is essentially a personal record of how Mr. Winsbury-White has managed the cases of urinary lithiasis which have come under his care. That he is able to draw from the records of 866 personal cases is sufficient recommendation of the practical value of the book.

The theoretical passages in the book are those most open to criticism, but this is probably due to the author's desire to keep the work down to its present size. It is quite evident that in the authory view practically all urinary calculi are formed as the result of infection. The importance of urinars' acidity and alkalinity from this point of view is discussed and here there is the all too common mathematical error of mixing indiscriminately $\mathrm{pH}$ and $\mathrm{H}$-ion concentration, and we have the statement 'That there are circumstances in which the high concentrations encourage the precipitation of phosphates. Huggins (1936) states that the $\mathrm{pH}$ should be above 6.9 for this to occur.'

The necessity for converting all figures into percentages is frequently misleading and in one place we read about an incidence of 5.2 per cent. of 19 cases, i.e. I, from which no conclusion can be drawn.

On the practical side there is little scope for criticism. On the subject of anuria it would perhaps have been better to have stressed the fact that the treatment advised was for calculous anuria only, and not for anuria due to any other cuuse. In the complications of nephrectomy the possibility of a duodenal fistula occurring is considered; the value of the advice under these circumstances of performing a gastro-enterostomy is open to doubt.

Among Mr. Winsbury-White's contra-indication for surgery is the advanced age of the patient. Obviously this is a factor, but it cannot be considered good practice to abandon someone to a painful and miserable existence purely because of their age. As Allison said on another subject, 'Too much attention is paid to the quantity of life, and insufficient to the quality.'

The book is well presented and set out, but at times some irritation was caused by the constant reference to figures many pages away.

Stone in the Urinary Tract will be of most value to the more junior general surgeons who have such cases under their care and who have not had specialist training. The advice given in the management of difficult cases will stand them in good stead.

J.W.P.G. 